\title{
Legalities of child marriage in Nigeria: Implications on health and strategies of prevention
}

\author{
Agege EA ${ }^{1}$, Nwose EU ${ }^{1,2 *}$, Odjimogho $\mathrm{S}^{1}$ and Igumbor $\mathrm{EO}^{1}$ \\ ${ }^{1}$ Department of Public and Community Health, Novena University Ogume, Nigeria \\ ${ }^{2}$ School of Community Health, Charles Sturt University, New South Wales, Australia
}

\begin{abstract}
Studies have shown that girls with three or fewer years of schooling are five times more likely than girls with eight or more years of schooling to marry before the age of 18 years old. There has been global struggle that highlighted the plight of uneducated girls in poor countries as being most vulnerable. The objective of this narrative is to highlight some of the legalities of child or early marriage in Nigeria. Three Case scenarios are presented together with their associated salient impacts that go beside and often worse than sexual health. In this endeavour, the case stories expatiate how cultural differences, religious practices, social orientation and conflicting laws constitute the legalities surrounding child or early marriages. In particular, attempt is made to elucidate the role of peer-pressure and social tension as well as the fact that culture, parents or religions are not only the culprits, but also the girls such as in analogy to teenage pregnancies. Recommendations of strategies for prevention articulated.
\end{abstract}

\section{Introduction}

At the Fourth World Conference on Women, Beijing, 1995, factors inhibiting the realisation of women's potentials including their health were addressed. Child marriage is recognised as one of the social malaise that needed to be eradicated to improve the quality of life of the girl child in the pursuit of sustainable development $[1,2]$. The discussion on child marriage has been going on for years, while the knowledge of forced marriage is never new. For instance, there has been research reports from 'Anti-Slavery International' on child marriage, and 'Save the Children' on early marriage [3]. What is confounding is that there legalities that mitigate against enforcement of statutory laws.

Nigeria is said to hold the world's record with the highest number of children out of school. The statistics as at 2013 indicated that only 12 countries had estimated 28.5 million children out-of-school and that this accounted for $47 \%$ of kids out of school population in the world. Among the twelve countries Nigeria ranked number one with over 10.5 children out of school [4]. The figure translates to Nigeria having $17.4 \%$ of the world's population of out-of-school children - with the country, Pakistan, in second position accounting for $8.4 \%$, which is less than half of Nigeria's figure (Figure 1).

A paper on legalities of child marriage in Nigeria had articulated some of the controversies as well as the impacts on socioeconomic development and health of the girl child [5]. The paper appeared to focus on culture and religion of the North-western Nigeria without much recourse to the South. Yet, feminization of poverty is a social phenomenon [2,6], and early marriage is a factor [7]. It is probably implicit that child marriage being a global issue is common in other parts of Nigeria, but the legalities are yet to be exhaustively narrated, especially in view of the peer-pressure or social tension [8]. Hence, the objective of this paper is to provide expanded narrative on the discourse.

\section{Legalities}

\section{Case scenarios}

Case scenario 1: A classical child marriage shrouded in legalities was published in 2015 [5, 9]. As recent as in April 2014, Wasilla was given out in marriage at the age of 14years old and against her consent to a 35years old man, Sani. According to the story: Wasila indicated that the marriage to the man was forced on her; and that she neither loves Sani, nor want to have a relationship with him. Wasila also told her

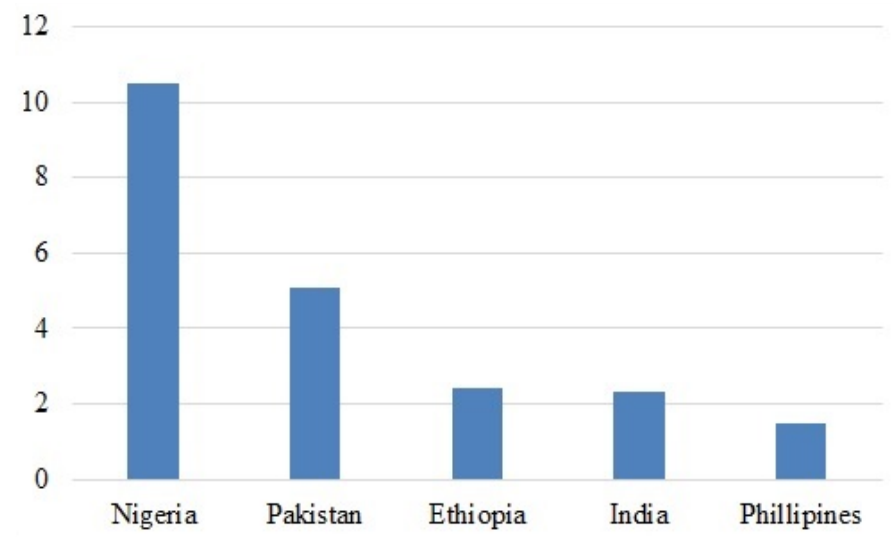

Figure 1. Top six countries with highest percentage of kids out of school - Nigeria ranks first with runner having less than half [4].

Correspondence to: Dr. Uba Nwose. School of Community Health, Charles Sturt University. Leeds Parade, Orange, NSW 2800 Australia, Tel: +612 63657282; E-mail: enwose@csu.edu.au

Key words: girls, early marriage, peer-pressure, social tension, stress

Received: August 12, 2017; Accepted: August 18, 2017; Published: August 24, 2017 
lawyer that she was tied to the bed and raped. Apparently, the husband died, and the girl was accused of killing her husband by food poisoning and had to stand trial for murder. The Court rejected a motion to have the murder charges quashed, in favour that the trial should proceed, which means that the child stands the risk of death penalty. This raised the issue of the legality of child marriage in Nigeria [5], but beside legal concern is health. If there is a public or sexual health impact of child marriage, death is the worst culmination of ill-health and here is a case example.

Case scenario 2: There is an unpublicized story of AO, who was given out in marriage before being informed. AO was a class 4 girl (Year 10 by Western 12years system) at Ogume Gramma School in rural Ukwani community of Ndokwa local government area of Delta State Nigeria; fatherless, and living with her 'single mother' and siblings at the time. She returned from school one afternoon to hear that her uncle (late father's brother) has visited from metropolitan Lagos. She was delighted to see her uncle, but was told that he has gone to 'family compound' for a family meeting. With excitement, a friend who has never seen any of AO's uncle waited with AO for the uncle's return for over 6hours until late into the night to no avail, and they both went to sleep. Later in the middle of night at about 2am, the uncle woke AO to give the 'Breaking News' with explanation: my daughter, it's because of you that I have come on this village visit. You know that since your father died, your security and welfare rests on our shoulder. This includes the burden of your going to school. A man has come to marry you and the family elders have agreed. The agreement is especially given two impetus that on one hand we don't have money to send you to school; on the other hand, the man agreed to train you. The first expression of disagreement and refusal by $\mathrm{AO}$ was meted with rearticulation that the dowry was paid that night hence he (the uncle) was late in the family meeting. Every form of expression of unacceptability by AO that she cannot be given out to marriage to a man he has never met and who also did not have the maturity to meet her was futile as she was practically forcefully carried to the husband's house in neighbouring village. The scenario and storyline developed further to the point of realization that this was a sort of parental arranged marriage for a man who appeared to have neither a job to return to, nor mental capacity to manage himself. AO attempted suicide after several failed attempts of escape. She did finally succeed to escape to the hands of a Godly family who supported her to complete secondary school and went on to become a nurse. However, sexual health was affected and post-traumatic stress disorder was managed for years.

Case stories scenario 3: $\mathrm{BI}$ has a basis of marriage that constitute another scenario worthy of articulation. She was in secondary class 2 (Year 8 by Western 12years system) at Abbi Girls Gramma School also in rural Ukwani community of Ndokwa local government area of Delta State Nigeria. One day, BI walked up to her parents that she wants to get married instead of being seen as 'a prostitute having boyfriend'. The parents agreed against the protests of older siblings. She got married to albeit likeable and well-talked-about self-employed carpenter living in the same farm village. Over time, family life and the stress of raising eight children took its toll. As at the time of writing this paper, BI never completed secondary school and it is humanly unthinkable luxury to be employable in any form of skilled labour. Yet, the stress of feeding eight children in a Nigerian rural village is compounded by inability to afford healthcare for the potentially stress-induced ill-health (prediabetes and periodontal disease) that she suffers. Moreso, her children are growing up suffering the psychological trauma of feeling poor.

\section{Narratives}

Child marriage is a complex and controversial issue in Nigeria and may be viewed differently depending on the context. There are wide disparaging views of the subject that can be based on four legalities including cultural differences, religious beliefs, social values, and conflict of laws $[5,8]$.

Culture: Child marriage is rooted in the cultural traditions of the Hausa-Fulani communities in Northwest Nigeria. Child brides often come from patriarchal societies where parents and elders play very significant or domineering roles in selecting spouses for their children. Strong cultural norms place emphasis on a girl's virginity, which is closely tied to a family honour. Parents are disposed to marrying off their daughters at a very tender age to ensure they marry as virgins and retain the family honour. The practice of child marriage is also strongly followed as a way of protecting the girl child from sexual assault and unwanted extra-marital or teenage pregnancies [8]. That is, given the facts regarding sexual activities among unmarried children as young as 10years old [10].

Meanwhile, it is pertinent to note from statistics presented by the former Central Bank Governor, Lamido, that in the part of Nigeria where Wasila comes from, as many as $93 \%$ of girls are being denied access to secondary education and up to $70 \%$ of women in the twenties (i.e., 20 - 29years old) are unable to read. Further, among the $7 \%$ that enrol in secondary school, it is less than half that completes [11].

Religious beliefs: The vast majority of child brides are from Mohammedan homes. To a large extent, the marriage culture is dictated by Islamic religious norms. Prepubescent marriage is a norm that is religiously encouraged - i.e. beside the belief that early marriage for a girl child maximises her childbearing potential. As Islam has permeated the socio-cultural life of the Hausa-Fulani, so has Islamic law and jurisprudence become assimilated into the native law and custom especially on issues of personal law relating to marriage and family life $[5,12]$.

Christianity also believe in virginity until marriage and would rather marry early than have premarital sex, which is deemed to be fornication and a sin. This was the basis of the scenario in John chapter eight of the bible. It remains a theme in pre-marriage counselling and also the meaning of white robe in church wedding. Extra-marital or pre-marital sex is still condemned as sin - e.g. "Flee from sexual immorality. All other sins a person commits are outside the body, but whoever sins sexually, sins against their own body. Do you not know that your bodies are temples of the Holy Spirit, who is in you, whom you have received from God?" (1 Corinthians 6). Hence, Christian youth are usually under peer-pressure and advised to marry early [13].

Social values: Case scenarios two and three about $\mathrm{AO}$ and $\mathrm{BI}$, respectively, were classical cases of early marriage motivated by social values. However, this factor of social values is most often subsumed in the generalization of sociocultural discourse until culture and religion are separated from the social. Indeed, the giving of AO to marriage would have been attributed to either religious practice if she and her family were Muslims, or the strong cultural norms of protecting family honour. Also, BI's case would have been explained as culture of protecting family integrity, if the idea of marrying early had come from her parents.

At this juncture, it must be emphasized that it is not the culture of Ogume or any Ukwani community to give a daughter in marriage without the girl's knowledge, let alone payment of dowry before telling 
her. Rather, this was a case of social tension underlying erroneous good intension. Similar scenarios abound in several communities - e.g. there was an identical case that occurred about three years' later at Eku community also involving fatherlessness and social tension around inability of the relatives to sponsor education as reason for forcing early marriage. The social tension driving these occurrences comes in form of peer pressure and 'negative affect' altruistic tendencies whereby African men try to show that they care about the children of their late brother. In the process, these uncles of fatherless girls are suffering stress that drives genuine negative affect altruism.

Although, the level of social tension surrounding such scenario has yet to be studied and quantified, it is explicitly articulated that child marriage is a practice that is primarily driven by poverty and economic status [14]. It can also be implied from developed countries like Australia, where social security (Centre Link) payments to the single mother and/or youth will provide for the fatherless children, as this is unavailable in Nigeria. The stress suffered by these uncles of fatherless girls ideally constitutes a public health issue as well as a logic difficult for any concerned person to challenge. Hence a legality.

In the case of $\mathrm{BI}$, it is imaginable that peer pressure vis-à-vis social tension to have sex was a factor. It is noteworthy that in the developed countries like Australia and United Kingdom, girls who get into teenage pregnancies do suffer some levels of backwardness and stress, despite financial supports from social security payments. Therefore, there is need to acknowledge that child marriage is not solely the fault of culture and religion, but also coercion from peer pressure driving some of the girls to naively initiate it themselves.[8] Recognizing the naivety factor and social perspectives is empirical to developing appropriate educational program that is holistic on child marriage.

Conflicting laws: The Convention on the Rights of the Child (CRC) that was adopted by the United Nations in November 1989 got ratified in Nigeria in March 1991. However, the actual legal definition is that "a child means every human being below the age of 18 years unless, under the law applicable to the child, the majority is attained earlier" It is pertinent to note the legality clause italicized in the quotation. This clause was a weak defence for the protection of child when Sani Ahmed Yerima, Nigeria Senator asserted that "Islamic Law allows marriage not by age but by maturity, which is attained once a girl reaches the age of puberty" [5].

Moreover, the law was supposed to render invalid any contravening custom or tradition including cultural and religious practices that are injurious to the child. Yet, the law has been ineffective in arresting the incidence of child marriage in some parts of nigeria.[5] The country is bound by federal laws, but a statutory law cannot be applied on marriages contracted under Customary or Islamic laws $[15,16]$. It has been reported from India that religious laws also mitigate against enforcement of rape legislations [3].

Arguably, teenage pregnancy is analogous to child marriage as the age at marriage and pregnancy similarly correlate in several settings[17]. Unfortunately, the same conflict of laws operates in the developed countries and promote child marriages in analogous formats. A case in point is where sexual exploitation is acknowledged to be a child protection issue until the age of 18years old, but there is conflicting legal provision for age of consent for sexual intercourse being 16. Also, sexual activity by children (i.e. under 18 years old) may be considered unlawful, but the same under-aged girl can attend sexual services without the knowledge of parents or guidance and she is still entitled to confidentiality [18]. Hence, a public health officer may become aware that a girl child is involved in unlawful sexual activity, but the law of confidentiality prevents invitation of her guidance to initiate strategies that can mitigate child marriage or teenage pregnancy.

\section{Public health strategies to reduce child marriage and their impacts}

Legislations to assist the public health workers to reach the girls at risk with targeted programs and services has been suggested as one potential step towards improving social protection for child brides [19]. For over half a century, it had been proposed that a system of courts (English, religious and customary) cannot be perpetuated indefinitely [20], and Sharia laws need to be addressed to curtail child marriage [21]. Apart from the laws, several other strategies could be designed to halt this practice and prevent its precarious outcomes [22].

Another suggestion has been that existing child-marriage prevention programs targeting unmarried girls should be broadened to include education of parents and also the men who might pursue young girls for marriage as well as provision of interventions for women already married as children [5,12,21]. Further effort to prevent early child marriage could be social change programs to provide education and job opportunities for girls in rural areas [23]. It is a known fact that education mitigates early marriage and empowers women [24-26].

\section{Support adolescent girls}

The need to focusing on the problems of youth and adolescents which was 1st identified in 1989 at a World Health Assembly. It was recognized that foreign cultures have armed youths to challenge both norms and parent (legality!!), while accessible accurate sex education was desperately needed. In this consideration, recourse was made to the facts that integrity and honesty of adults are sometimes doubtful, while peer pressure and social tension are operating especially with girls being more vulnerable [27]. Although the focus is on communities preventing child marriage, young girls who have already married also need support. As well as being isolated and having less chance to complete or continue their education, child marriage can put young girls at a higher risk of violence in the home- sexually, physically and psychologically. For instance, the Case of BI may never be as sad in developed countries where social security payments exist.

Include 'conflicting legalities' in sexual health service education against child marriage. One of the most powerful tools that anti-child marriage organisations and women's rights activists and advocates have been campaigning for is for governments in countries such as Yemen where child marriage is prevalent to make child marriage illegal by raising the legal age of marriage to the minimum age of 18years old [22]. Where there are legislations and laws conflicting with religious or traditions norms [20], a very dispassionate dialogue to help prevent child marriage by organising a forum discussion between the relevant authorities or agencies is necessary.

\section{Conclusion and recommendations}

The objective of this work was to narratively review the legalities of girl child marriage. The magnitude of the problem can be intimidating, just as the public health concern may involve worst case scenarios being death by either court's order or suicide. Efforts should bring in public attention to develop and implement holistic policy proposals towards stopping child marriages and ensure legal protection to girls. It may be necessary to start at community levels and with evaluation of perspectives of both girls and parents. 


\section{Acknowledgement}

This work is the first part and a prelude to a Master of Public Health work on perceptions on the factors relating to early marriage by girls.

\section{References}

1. World Conference on Women (4th: 1995: Beijing) London Roundtable on Women's Health. (1995) Statement of the London Roundtable on Women's Health for the Fourth World Conference on Women (FWCW), 7 January 1995. Plan Parent Eur 24: 24-26. [Crossref]

2. Friedman S (1998) Girls: a key to the future. People Planet 7: 6-9. [Crossref]

3. Ouattara M, Sen P, Thomson M (1998) Forced marriage, forced sex: the perils of childhood for girls. Gend Dev 6: 27-33. [Crossref]

4. Abdulmalik A (2013) SHOCKING: Nigeria holds world record in number of children out of school. Premium Times; June 11.

5. Fayokun KO (2015) Legality of child marriage in Nigeria and Inhibitions Against Realisation of Education Rights. US-China Law Rev 12: 812

6. Goldberg G (1998) The Feminization of Poverty: Here to Stay? The Brown Journal of World Affairs 5: 161-186.

7. Otoo-Oyortey N, Pobi S (2003) Early marriage and poverty: exploring links and key policy issues. Gender \& Development 11: 42-51.

8. Aduayi VA, Aduayi OS, Olasode OA (2016) Sexual coercion and violence among young women in Nigeria: a northern and southern comparison. African Journal of Reproductive Health 20: 37-43.

9. Ajumobi F (2014) Nigeria and the Ills of Child Marriage. Vanguard Nigeria News Paper Nigeria: May.May 25:4-5.

10. Olasode OA. (2007) Sexual behaviour in adolescents and young people attending a sexually transmitted disease clinic, Ile Ife, Nigeria. Indian J Sex Transm Dis. 28: 83-86.

11. Sanusi L. National commission for mass literacy, adult and non formal education 2013 [cited May 1312 August, 2017].

12. Braimah TS (2014) Child marriage in Northern Nigeria: Section 61 of Part I of the 1999 Constitution and the protection of children against child marriage. African Human Rights Law Journal 14: 474-88.
13. Barrick A (2012) Pastor to young Christians: Get married early [Internet].

14. Manganara J. President's letter: Child marriage - a practice driven by poverty 2016 [cited December 1212 August, 2017].

15. FAO. Nigeria: Discrepancies/gaps between statutory and customary laws 2017 [12th August, 2017].

16. Chindah T. Nigeria's Child Rights Act: Ratification, implementation and domestication 2016 [4th August, 2017].

17. Psaki S (2016) Addressing child marriage and adolescent pregnancy as barriers to gender parity and equality in education. PROSPECTS. 46: 109-129.

18. Rogstad KE, King H (2003) Child protection issues and sexual health services in the UK. J Fam Plann Reprod Health Care 29: 182-183.

19. Machel G, Pires E, Carlsson G (2013) The world we want: an end to child marriage. Lancet 382: 1005-1006. [Crossref]

20. Anderson J (1960) Colonial law in tropical Africa: The conflict between English, Islamic and Customary law. Indiana Law Journal 35: 228-234.

21. Duvall EM (1965) How effective are marriage courses? Journal of Marriage and the Family 27: 176-184.

22. Blake M. Yemeni child bride, eight, dies of internal injuries on first night of forced marriage to groom five times her age. Daily Mail, Australia. 2016.

23. Raj A, Saggurti N, Balaiah D, Silverman JG (2009) Prevalence of child marriage and its effect on fertility and fertility-control outcomes of young women in India: a crosssectional, observational study. The Lancet 373: 1883-1889.

24. Sabbe A, Oulami H, Zekraoui W, Hikmat H, Temmerman M, et al. (2013) Determinants of child and forced marriage in Morocco: stakeholder perspectives on health, policies and human rights. BMC Int Health Hum Rights 13: 43.

25. Singh MM, Ashok L, Binu VS, Parsekar SS, Bhumika TV (2015) Adolescents and Body Image: A Cross Sectional Study. Indian J Pediatr 82: 1107-1111. [Crossref]

26. Erulkar AS, Muthengi E (2009) Evaluation of Berhane Hewan: a program to delay child marriage in rural Ethiopia. Int Perspect Sex Reprod Health 35: 6-14. [Crossref]

27. Ransome-Kuti O (1992) Keynote address at the Fifth Congress of the International Association for Adolescent Health. J Adolesc Health 13: 342-344. [Crossref]

Copyright: $\odot 2017$ Agege EA. This is an open-access article distributed under the terms of the Creative Commons Attribution License, which permits unrestricted use, distribution, and reproduction in any medium, provided the original author and source are credited. 